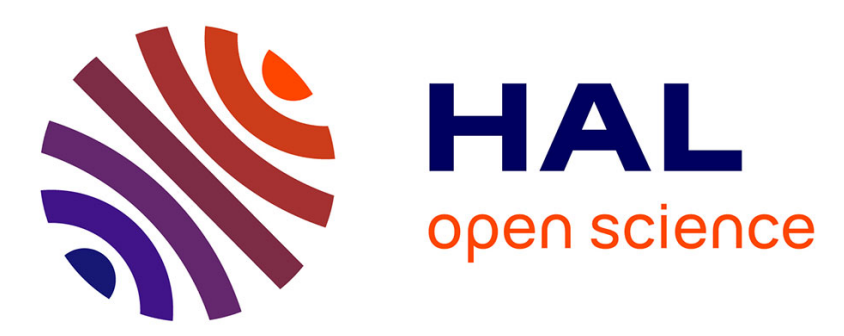

\title{
Computational Efficiency of Optic Disk Detection on Fundus Image: A survey
}

Sofien Ben Sayadia, Yaroub Elloumi, Mohamed Akil, Mohamed Hedibedoui

\section{To cite this version:}

Sofien Ben Sayadia, Yaroub Elloumi, Mohamed Akil, Mohamed Hedibedoui. Computational Efficiency of Optic Disk Detection on Fundus Image: A survey. SPIE Real-Time Image and Video Processing, Apr 2018, Orlando, United States. hal-01796769

\section{HAL Id: hal-01796769 https://hal.science/hal-01796769}

Submitted on 22 May 2018

HAL is a multi-disciplinary open access archive for the deposit and dissemination of scientific research documents, whether they are published or not. The documents may come from teaching and research institutions in France or abroad, or from public or private research centers.
L'archive ouverte pluridisciplinaire HAL, est destinée au dépôt et à la diffusion de documents scientifiques de niveau recherche, publiés ou non, émanant des établissements d'enseignement et de recherche français ou étrangers, des laboratoires publics ou privés. 


\title{
Computational Efficiency of Optic Disk Detection on Fundus Image: A survey
}

\author{
Sofien Ben Sayadia ${ }^{\mathrm{a}}$, YaroubElloumi ${ }^{\mathrm{a}, \mathrm{b}}$, Mohamed Akil ${ }^{\mathrm{b}}$, Mohamed HediBedoui ${ }^{\mathrm{a}}$ \\ ${ }^{a}$ Medical Technology and Image Processing Laboratory, Faculty of medicine, University of Monastir, Tunisia. \\ ${ }^{\mathrm{b}}$ Gaspard Monge Computer Science Laboratory, ESIEE-Paris, University Paris-Est Marne-la-Vallée, France.
}

\begin{abstract}
Fundus image processing is getting widely used in retinopathy detection. Detection approaches always proceed to identify the retinal components, where optic disk is one of the principal ones. It is characterized by: a higher brightness compared to the eye fundus, a circular shape and convergence of blood vessels on it. As a consequence, different approaches for optic disk detection have been proposed. To ensure a higher performing detection, those approaches varied in terms of characteristics set chosen to detect the optic disk. Even the performances are slightly different, we distinguish a significant gap on the computational complexity and hence on the execution time.

This paper focuses on the survey of the approaches for optic disk detection. To identify an efficient approach, it is relevant to explore the chosen characteristics and the proposed processing to locate the optic disk. For this purpose, we analyze the computational complexity of each detection approach. Then, we propose a classification approach in terms of computational efficiency. In this comparison study, we distinguish a relation between computational complexity and the characteristic set for OD detection.
\end{abstract}

Keywords: Fundus image, optic disk detection, computational complexity.

\section{INTRODUCTION}

Optic disk (OD) detection is an important step in many computer-aided diagnostic systems to assist in the detection and diagnosis of ophthalmic conditions such as diabetic retinopathy, glaucoma and age-related macular degeneration.In an image of the retinal fundus such as illustrated in fig.1.(a), the OD appeared usually as a relatively circular yellowish disk having an average diameter of $1600 \mu \mathrm{m}$ [1]. The shape of the OD is similar to an ellipse with a width of $1.8 \pm 0.2 \mathrm{~mm}$ and a length of $1.9 \pm 0.2 \mathrm{~mm}$ [5]. ODis usually brighter than the fundus [4]. It is also the region where retinal vessels emerge and spread, covering the retina [6,7, and 2].However, significant changes in shape, color and depth is an indicator of various ophthalmic pathologies. Variations in color or intensity are considerable following either dark hemorrhages or bright exudates. Thus, the ODis affected by hypertensive retinopathy[10]andby the new abnormal blood vessels (neovascularization) that are caused by Proliferative Diabetic Retinopathy (PDR) [13, 16].

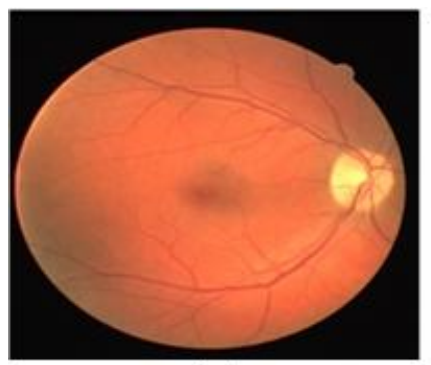

(a)

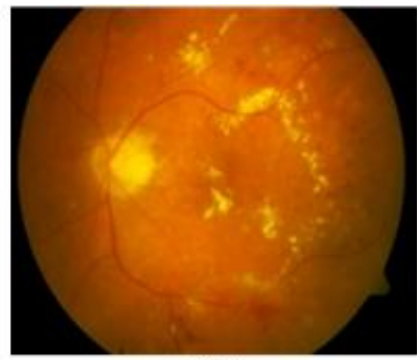

(b)

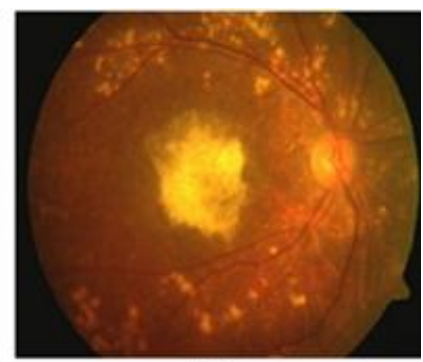

(c)

Figure 1. (a) A healthy fundus image; (b) brightnessExudatesin diabetic retinopathy; (c) dry AMD

These changes provide quantitative metrics for the detection of pathologies associated with OD. ODdetection also helps segmenting other features into healthyor pathological images. Information on ODcan be used in the severity ranking of 
ocular diseases such as glaucoma by measuring the ratio between OD and optical cup diameters [10]. In case of diabetic retinopathy and AMD, the OD region should identified in order to avoid confusion with retinal exudates and dry AMD lesions $[15,14]$, which are shown respectively in fig.1.(b) and fig.1.(c).

A significant number OD location methods are proposed in the literature. Each method aims to identifying the OD location with respect to lesions. RecentOD location approaches offer higher and similar detection performances. Several approaches are evaluated using a similar experimentation in terms of performance metrics and public databases. Nevertheless, we cannot distinguish an optimal approach. However, the proposed approaches differ in terms of the characteristics employed to detect OD, which leads to an important difference in terms of execution time.Moreover, experimental evaluations are performed using public image databases with lowered resolution such as the resolutions of STARE and DRIVE that are equal to $(700 \times 605)$ and $(564 \times 584)$, respectively. These images are characterized by lower resolutions than those currently generated by the actual retinographs such as the "TRC-NW 7 SF"retinographhaving a resolution of (3008 x 2000) [12]. Furthermore, retinograph resolution is still in permanent rise. Thus, the execution times indicated in OD location approaches can't taking into account even for comparing or implementing proposed methods. The objective of our work is to perform a comparative study of ODdetection methods. This study consists in algorithmically studying the steps in order to generate their algorithmic complexities. The challenge of this work is to standardize the complexity values despite the divergence of the parameters and algorithmic structures employed.The remaining sections of this manuscript are organized as follows: Section II described relevantOD detection methods. In section III, we presenta classification of OD detection methods s in terms of OD characteristics. In Section IV, we figure out and normalize the computational complexities of OD detection methods s. Finally, those Complexities are discussed and synthesized in section $\mathrm{V}$.

\section{METHODSOF OD DETECTION}

In the work of Pourreza et al. [1], the OD is detected basing on brightness and roundness. Therefore, the radon transform is performed to compute the intensity. The radon transform is applied with several angles to eachsub-window in the objective of detecting roundness. The center of the sub-image is considered as the center of the OD. Foracchia et al. [10] used a parametric geometric model (parabolic path) to describe the typical direction of the retinal vessels as they converge on the optical disc. Youssif et al. [11] used the directional pattern of retinal blood vessels for the OD detection. Mahfouz et al. [3] combined three characteristics which are the disk brightness, the vessel convergence and the vascular direction. In the work of Hashim et al. [4], a binary mask is applied on the intensity channel to exclude the background pixels. Then, morphological operators and contrast enhancement techniques (Gamma transformations) are used in conjunction with the difference of the Gaussian filter (DOG) to obtain the OD border.

In the work proposed by Rahebi et al. [5], a median filter in performed to denoising the retinal fundus image. Then, the optical disk center is determined using the Firefly that moves towards a pixel of high intensity. In the method proposed in [6], density, compactness and uniformityof blood vessels are formulated to find the OD coordinates. In the work described in [7], the vessel enhancement is combined with morphological operators to detect orientations of the 4 main vessels. Xiong and $\mathrm{Li}$ [8] have proposed an a method for locating the OD center by extracting a variety of features including vertical and horizontal vessel intensityand the size of the bright object. In the work of Giraddi et al. [9], a thresholdingis employed to eliminate false positive brightness shape. The OD segmentation is then performed using the vector field gradient (GVF snake). The limitations and strengths of each technique, as well as the success rate for each database, are briefly explained in Table 1 .

\section{METHOD CLASSIFICATION IN TERMS OF OD CRITERIA}

The described techniques can be classified according to the used criteria:DO brightness, DO roundness and vesselshape and orientation. In healthy retinal images, the OD is able to be automatically located due to the well-defined characteristics. Nevertheless, developing fast and robust methods for the automatic localization of OD can be very difficult due to the presence of retinal pathology lesions. These pathologies cause changes in the OD criteria: the brightness and shape are confused with the presence of lesions havingsimilar properties than OD such as exudates, AMD. The presence of lesions near from ODbrings to detect an oversized OD. Furthermore, some retinal pathology such as neovascularization (DR), wet AMD, leads to provide mistaken vessel characteristics.

The work described in $[1,4,5,9]$ have proposed usingOD features such as brightness, shape and size. The work [10,6] uses vascularization information and is based on the fact that the vessels emerge from the OD. The work reported in [3, 11, 7, and 8] employs both brightness and vessel convergence to automatically detectOD, such as reported in Table. 2. 
Table1. Summary of OD detection methods

\begin{tabular}{|c|c|c|c|c|}
\hline Authors & Year & Highlights/limitations & database & accuracy \\
\hline R.Pourreza.S et al.[1] & 2014 & $\begin{array}{l}\text {-Susceptible to lesion with bright and size } \\
\text { similar to OD }\end{array}$ & $\begin{array}{l}\text { STARE, } \\
\text { DRIVE, } \\
\text { MUMS-DB, } \\
\text { MUMS-DB(FA) }\end{array}$ & $\begin{array}{l}96.3 \% \\
100 \% \\
97.5 \% \\
91.3 \%\end{array}$ \\
\hline M. Foracchia et al. [10] & 2004 & $\begin{array}{l}\text {-Susceptible to incomplete construction of } \\
\text { the vascular structure. }\end{array}$ & STARE & $98 \%$ \\
\hline A. Youssif et al. [11] & 2008 & Susceptible to the lack of sizable vessels & $\begin{array}{l}\text { STARE } \\
\text { DRIVE }\end{array}$ & $\begin{array}{c}98.77 \% \\
100 \%\end{array}$ \\
\hline E.Mahfouz et al.[3] & 2010 & $\begin{array}{l}\text {-Susceptible to incomplete OD appearance. } \\
\text { - Susceptible to bright lesion }\end{array}$ & $\begin{array}{c}\text { STARE } \\
\text { DRIVE } \\
\text { DIARETDB1 } \\
\text { DIARETDB0 }\end{array}$ & $\begin{array}{l}92.6 \% \\
100 \% \\
97.8 \% \\
98.5 \%\end{array}$ \\
\hline F.A.Hashim et al. [4] & 2015 & $\begin{array}{l}\text {-Susceptible to Lesion with bright and size } \\
\text { similar to OD } \\
\text { - method is not fully automatic }\end{array}$ & $\begin{array}{l}\text { STARE } \\
\text { DRIVE } \\
\text { DIARETDB1 } \\
\text { DIARETDB0 } \\
\text { ARIA } \\
\text { MESSIDOR } \\
\end{array}$ & $\begin{array}{c}98.8 \% \\
100 \% \\
100 \% \\
100 \% \\
100 \% \\
99.83 \%\end{array}$ \\
\hline JavadRahebi et al.[5] & 2016 & $\begin{array}{l}\text {-Susceptible to bright Lesion. } \\
\text {-Tested on healthy images only. }\end{array}$ & $\begin{array}{c}\text { STARE } \\
\text { DRIVE } \\
\text { DIARETDB1 } \\
\end{array}$ & $\begin{array}{c}95 \% \\
100 \% \\
94.38 \% \\
\end{array}$ \\
\hline DongboZhang et al.[6] & 2016 & $\begin{array}{l}\text {-Robust in OD appearance change. } \\
\text {-Susceptible to incomplete construction of } \\
\text { the vascular structure. }\end{array}$ & $\begin{array}{c}\text { STARE } \\
\text { DRIVE } \\
\text { DIARETDB1 } \\
\text { DIARETDB0 } \\
\end{array}$ & $\begin{array}{l}98.8 \% \\
99.7 \%\end{array}$ \\
\hline Ivo Soareset al.[7] & 2016 & $\begin{array}{l}\text { Susceptible to low contrast and absence of } \\
\text { the principal vascular. }\end{array}$ & $\begin{array}{c}\text { STARE } \\
\text { DRIVE } \\
\text { DIARETDB1 } \\
\text { DIARETDB0 } \\
\text { MESSIDOR } \\
\text { ROC } \\
\text { E-OPHTHA-EX } \\
\text { HRF } \\
\end{array}$ & $\begin{array}{c}98.77 \% \\
100 \% \\
98.88 \% \\
98.46 \% \\
99.25 \% \\
99.00 \% \\
98.78 \% \\
100 \% \\
\end{array}$ \\
\hline Xiong et $\mathrm{Li}[8]$ & 2016 & $\begin{array}{c}\text {-Susceptible to quality of images. } \\
\text { - Robust in OD incomplete appearance and } \\
\text { change. } \\
\text {-Robust in vessels are not obviousin retinal } \\
\text { images } \\
\text { - robust in lesion with bright and size } \\
\text { similar to OD }\end{array}$ & $\begin{array}{c}\text { STARE } \\
\text { DRIVE } \\
\text { DIARETDB1 } \\
\text { DIARETDB0 }\end{array}$ & $\begin{array}{l}95.8 \% \\
100 \% \\
97.8 \% \\
99.2 \%\end{array}$ \\
\hline S.Giraddi et al. [9] & 2017 & $\begin{array}{l}\text {-Susceptible to The poor quality of images. } \\
\text {-Susceptible to lesion with bright and size } \\
\text { similar to OD. }\end{array}$ & $\begin{array}{c}\text { DRIVE } \\
\text { DIARETDB1 } \\
\text { DIARETDB0 }\end{array}$ & $\begin{array}{c}100 \% \\
97.75 \% \\
97.69 \%\end{array}$ \\
\hline
\end{tabular}

\section{COMPUTATIONAL COMPLEXITY OF OD DETECTION METHODS:}

The objective of this section is to compare the complexities of OD detection methods. Generally, an ODdetection methodfollows3 mainly steps: (1) Pre-processing: Reduce the effect of different artifacts; (2) predict OD positions and 
(3) Identify final OD location.Table 3 presents a comparison between the complexities of the methods studied. Thus, the complexity of each mainly steps is computed.

Based on the circular aspect of the retina, we consider that fundus image resolution is equal to ( $n * n)$. The complexities are expressed in terms of $n$ values andother parameter related in the "Notations" column. To maintain uniformity, OD diameter and vessel thickness should be assigned automatically from the image resolution. Basing on method complexity, we deduce that some parameters are evoked in several works, such as the OD size and the vessel width. Some other parameters are in relation with fundus image or retinal component sizes. Thus, we aim to normalize complexities by reducing the evoked parameters. Thus, we proceed to approximate them with respect to the $n$ image size, such as reported in "complexity normalization" column.

Table2. Summary of OD detection criteria.

\begin{tabular}{|l|c|c|c|c|}
\hline \multirow{2}{*}{ Names of Authors } & \multicolumn{4}{c|}{ Features } \\
\cline { 2 - 5 } & Brilliance & Circularity & Size & $\begin{array}{c}\text { Vessels } \\
\text { convergence }\end{array}$ \\
\hline R.Pourreza.S et al.[1] & $\bullet$ & $\bullet$ & $\bullet$ & $\bullet$ \\
\hline M. Foracchia et al. [10] & & & & $\bullet$ \\
\hline A. Youssif et al. [11] & $\bullet$ & & & $\bullet$ \\
\hline E.Mahfouz et al.[3] & $\bullet$ & & $\bullet$ & $\bullet$ \\
\hline F.A.Hashim et al.[4] & $\bullet$ & $\bullet$ & & $\bullet$ \\
\hline JavadRahebi et al.[5] & $\bullet$ & & & $\bullet$ \\
\hline DongboZhang et al.[6] & & & & $\bullet$ \\
\hline Ivo Soares et al.[7] & $\bullet$ & $\bullet$ & & $\bullet$ \\
\hline Xiong et Li [8] & $\bullet$ & $\bullet$ & & \\
\hline S.Giraddi et al. [9] & $\bullet$ & $\bullet$ & & $\bullet$ \\
\hline
\end{tabular}

\section{a. OD size Vs retina size :}

In [1], the OD size is experimentally approximated to 79, 130 and 313 pixels respectively for the databases DRIVE (564 $\times 584)$, STARE $(700 \times 605)$ and MUMS-DB $(2896 \times 1944)$. The ratio between retinal image diameter and the OD diameter is approximatelyn/7for DRIVE, $n / 5$ for STARE and $n / 9$ for MUMS-DB. In the work of Hashim et al [4], it is noted that the ODis shown in $(80 * 80)$ sub-image form image having resolution equal to $(570 \times 550)$, which represents $1 / 7$ of the fundus image. Soares et al. [7] note that, for a retinal image resolution equal to $(700 \times 600)$, the OD has a diameter equal to 80 pixels. In the work proposed in [9], the diameter is in the range of 80-100 pixels for resized image resolution at $\left(575^{*} 750\right)$ pixels. The ratio of retina diameter and OD diameter is approximately equal ton/(5 9)and $n /(6 \sim 8)$ respectively for the works relatedin [7] and [9], respectively. Thus, the diameter of OD can be approximated after the segmentation of FOV with:

$$
D_{O D}=\frac{1}{5 \sim 8} \times D_{F O V}[6]
$$

Where, $\mathrm{D}_{\mathrm{OD}}$ is the diameter of the OD.The ratio of the diameter of the retinal image to the OD diameter is approximately constant. According to the above relationship, we can unify the OD diameter by assigning the ratio to 7 for all complexity of studied methods. The diameter of DO is calculated with the following relation:

\section{b. vessel width Vs retina size :}

$$
D_{O D}=\frac{1}{7} \times n
$$

The work described in [10] indicates that the pixel number identified when segment vesselsis from 4300 to 7800 in a fundus image composed by $4.2 * 10^{4}$ pixels. The blood vessel is generally assumed to be no wider than 15 pixels [4], with a thickness of $15 \%$ of the OD diameter [3]. The ratio of OD diameter to the thickness of the main vessels is 
approximately equal to $1 /(6 \sim 7)[6]$.According the $\mathrm{D}_{\mathrm{OD}}$ relationship and assigning the ratio to 6.5 , the thickness is calculated with the following relation:

$$
E_{V P}=\frac{1}{6.5} \times D_{O D}=\frac{1}{45.5} \times n
$$

Where, $\mathrm{E}_{\mathrm{VP}}$ is the thickness of the main vessels.

Table3. Comparison of the computational complexity of ONH detectionmethods.

\begin{tabular}{|c|c|c|c|c|c|}
\hline \multirow[b]{2}{*}{ Authors } & \multirow[b]{2}{*}{ Complexity } & \multirow[b]{2}{*}{ Notations } & \multicolumn{3}{|c|}{ Complexity normalization } \\
\hline & & & $\begin{array}{l}\text { Preproce } \\
\text { ssing }\end{array}$ & $\begin{array}{l}\text { predicted } \\
\text { positions }\end{array}$ & $\begin{array}{c}\text { OD } \\
\text { location }\end{array}$ \\
\hline $\begin{array}{l}\text { R.Pourreza.S et } \\
\text { al.[1] }\end{array}$ & $n^{2}+9 n^{2} \varnothing P^{2}+3 \varnothing w c$ & $\begin{array}{l}\mathrm{P}=4, \varnothing=12, \\
\mathrm{w}=130 \\
\mathrm{c}=15\end{array}$ & $\mathrm{n}^{2}$ & 2. $10^{2} \cdot \mathrm{n}^{2}$ & $77 n$ \\
\hline $\begin{array}{l}\text { M. Foracchia et } \\
\text { al. [10] }\end{array}$ & $24 . n^{2} .16^{2}+180 . I .300$ & I: 6 & -- & $6.10^{3} \cdot n^{2}+324 \cdot 10^{3}$ & -- \\
\hline $\begin{array}{l}\text { A. Youssif et al. } \\
{[11]}\end{array}$ & $\begin{array}{c}\mathrm{n}^{2} \cdot\left(\mathrm{W}_{1}^{2}+2 \mathrm{~W}_{2}^{2}+24 \mathrm{~V}^{2}+1\right. \\
5)+\mathrm{V}^{2} \cdot 4 \cdot \mathrm{CW}_{4}^{2}\end{array}$ & $\begin{array}{l}W 1=40 \\
W 2=80 \\
V=(\text { vessel width }) \\
W 4=40 \\
C=6050 \text { number } \\
\text { ofpixels covered by } \\
\text { vessels }\end{array}$ & $15 . n^{2}$ & $12 \cdot 10^{-3} \cdot n^{4}+41 \cdot n^{2}$ & -- \\
\hline $\begin{array}{l}\text { E.Mahfouz et } \\
\text { al.[3] }\end{array}$ & $\begin{array}{l}\mathrm{n}^{2} \cdot(10+2 \cdot V)+2 \cdot n \cdot \mathrm{W}^{2} \\
+4 \mathrm{~W}^{2}\end{array}$ & $\begin{array}{l}\mathrm{W}=130 \\
\text { (ONH size) } \\
\mathrm{V}=\text { vesselwidth }\end{array}$ & $10 . n^{2}$ & $85 \cdot 10^{-3} \cdot n^{3}$ & $\begin{array}{l}82.10^{-} \\
{ }^{3} \cdot \mathrm{n}^{2}\end{array}$ \\
\hline $\begin{array}{l}\text { F.A.Hashim et } \\
\text { al.[4] }\end{array}$ & $\mathrm{n}^{2} \cdot\left(15^{2}+12+31\right)$ & & $10 . n^{2}$ & $258 . n^{2}$ & - \\
\hline $\begin{array}{l}\text { JavadRahebi et } \\
\text { al.[5] }\end{array}$ & $\mathrm{n}^{2} \cdot 15^{2}+\mathrm{I} \cdot \mathrm{F} \cdot(22+6 \mathrm{~F})$ & $\begin{array}{l}\mathrm{F}=100: \text { number de } \\
\text { firefly, } \\
\mathrm{I}=100 \text { (no Iteration) }\end{array}$ & $\mathrm{n}^{2}$ & $8.10^{4} \cdot n^{2}$ & - - \\
\hline $\begin{array}{l}\text { Dong boZhang et } \\
\text { al.[6] }\end{array}$ & $\begin{array}{l}\mathrm{n}^{2} . \\
\left(105 . \varnothing+2 . V \cdot n x .+10^{2}\right)+ \\
\text { n.V.C }\end{array}$ & $\begin{array}{l}\mathrm{C}=5 \\
\mathrm{~V}: \text { vessels width } \\
\varnothing=12 \\
\mathrm{nx}=13\end{array}$ & $\mathrm{n}^{2}$ & $4 . n^{3}+1100 . n^{2}$ & $2 . n^{2}$ \\
\hline $\begin{array}{l}\text { Ivo Soares et } \\
\text { al.[7] }\end{array}$ & $\mathrm{n}^{2} \cdot\left(91+80 \mathrm{~S}^{2}+\mathrm{d}+25 \mathrm{~W}^{2}\right)$ & $\begin{array}{l}\mathrm{S}=25 \text { size element } \\
\text { structurel } \\
\mathrm{W}=\text { size } \mathrm{ONH} \\
\mathrm{d}=\mathrm{dh}+\mathrm{dv} \text { :iteration des } \\
\text { divisions }\end{array}$ & $28 . n^{2}$ & $\begin{array}{c}37 \cdot 10^{-} \\
{ }^{3} \cdot n^{3}+50 \cdot 10^{3} \cdot n^{2}\end{array}$ & $\begin{array}{l}51 \cdot 10^{-} \\
2 \cdot n^{2}\end{array}$ \\
\hline Xiong et Li [8]] & $\begin{array}{l}\mathrm{n}^{2} \cdot\left(26+2 \mathrm{~V}+\mathrm{S}^{2}+\mathrm{S} 2^{2}\right)+ \\
\mathrm{C} 1\left(\mathrm{n} \cdot \mathrm{W}^{2}+\mathrm{W}_{1}^{2}+\mathrm{n} \cdot \mathrm{W}_{1}\right)+ \\
\left.4 \mathrm{CW}_{2}\right)\end{array}$ & $\begin{array}{l}\mathrm{S} 1=8 \\
\mathrm{~S} 2=10 \\
\mathrm{~W}=\text { size onh } \\
\mathrm{W} 1=140 \\
\mathrm{~W} 2=70 * 60 \\
\mathrm{C}=15 \text { candidate total. } \\
\mathrm{C} 1=8 \text { : candidate initial }\end{array}$ & $16 . n^{2}$ & $\begin{array}{c}21 \cdot 10^{-} \\
{ }^{3} \cdot \mathrm{n}^{3}+174 \cdot \mathrm{n}^{2}+157 \\
10^{3}\end{array}$ & $\begin{array}{c}10^{3} \cdot n+252 \\
.10^{3}\end{array}$ \\
\hline Giraddi et al. [9] & $\begin{array}{l}\mathrm{MN}(3+\mathrm{w})+ \\
\mathrm{W} .(3+13 . \mathrm{I})\end{array}$ & $\begin{array}{l}\text { W : onh size } \\
\mathrm{I}=200\end{array}$ & $\mathrm{n}^{2}$ & $14 \cdot 10^{2} \cdot n^{3}+2 \cdot n^{2}$ & $372 . n$ \\
\hline
\end{tabular}

\section{COMPLEXITY SYNTHESIS}

The preprocessing steps are always based on basic morphologic operators or thresholding processing. The mainly objectives are the extractionof retina and retinal components, theenhancement of image contrast [7, 4, 3, 1], orthe denoising[5]. It can be seen in Table 3 that all preprocessing have complexity between $\mathrm{n}^{2}$ and 28. $\mathrm{n}^{2}$. We deduce that preprocessing complexity is quadratic with order of $\mathrm{O}\left(\mathrm{n}^{2}\right)$. Themethods, whose location is based on the OD 
characteristics, proceed to detect all shapes with respect to the brightest and roundness using standard processing such as intensity threshold [9], Difference of Gaussian (DOG) filter [4] and principal component analysis [5]. These processing have quadratic processing complexity, of the order of $\mathrm{O}\left(\mathrm{n}^{2}\right)$ such as the worksdescribed in $[1,4$, and 5]. We distinguish that the work related in [9] is the only technique, whose detection is based on OD characteristics, having a cubic complexity in order of $\mathrm{O}\left(\mathrm{n}^{3}\right)$.

However, the methods that require the extraction and analysis of retinal vessel structure employ advanced processing such as geometric models [10], the convergence of vascularization [7] and the corresponding transformation to the direction of Vessels (General Hough Transformation GHT) [6]. Therefore, they involve a raised execution time. The works related in $[6,7,8]$, havecubic complexities in order of $\mathrm{O}\left(\mathrm{n}^{3}\right)$ while the work proposed by Youssif et al. [11] has a complexity in order of $\mathrm{O}\left(\mathrm{n}^{4}\right)$. On the same method category, we deduce that only the work proposed by Foracchia et al. [10] proposes a computational performing method with a quadratic complexity.

Some methods identify the OD onthemainly processing $[4,5,10$, and 11]. Other methods proceed to extract candidate list of OD locations. Thereafter, the OD location is performed by computing parameter for each candidate such as MSE orientation error [6], scoring index [3], etc., and hence locating OD. This principle leads to improve the robustness of their techniques with respect to the eventual lesions. The complexities of "ONH location" are in order of $\mathrm{O}\left(\mathrm{n}^{2}\right)$ for the works described in $[6,7,3]$, and have a linear complexity in order of $\mathrm{O}(\mathrm{n})$ in the works related in $[1,8,9]$.

In summary, we proved through all works that "predicted positions" processing requires an important computational complexity than preprocessing and OD location. Thus, the complexity of the whole method is similar to the complexity of the "predicted positions" processing. Consequently, the majority of methods that locate OD based on vessel convergence, are characterized by a complexity equal to $\mathrm{O}\left(\mathrm{n}^{3}\right)$. On the other side, methods based on OD characteristics require $\mathrm{O}\left(\mathrm{n}^{2}\right)$ to be performed.

\section{CONCLUSION AND FUTURE WORKS}

Several works are proposed to detect OD in fundus image. While their performance detection are similar, we distinguished a divergence in terms of execution times. Therefore, the main challenge of our work is to propose an approach to evaluate methods in terms of computational behavior. In this objective, we propose a classification of methods in terms of criteria evoked to detect OD. Thereafter, we propose to normalize their complexities in order to formulate them with standard parameters. The computed complexity allows distinguishing relation between criteria detection and complexity. We deduce that method aiming to detect OD based on OD characteristics requires less computational complexity than those detecting OD based on vessel convergence.

This study allows quantifying the computational behavior of any OD detection method independently from fundus image resolution. Moreover, it permits to compare between methods and hence to choose the adequate one for a real time implementation. In our future works, we aim to exploring the susceptible parallelism on methods in order to decrease complexity and hence execution time.

\section{REFERENCES}

[1] R.Pourreza.S ,MeysamTavakoli and Nasser Kehtarnavaz., "Computationally efficient optic nerve head detection in retinal fundus images," BiomedicalSignal Processing and Control, 63-73(2014).

[2] A. Fraga, N. Barreira, M. Ortega, M.G. Penedo, and M.J. Carreira., "Precise Segmentation of the Optic Disc in Retinal Fundus Images.," EUROCAST, Part I: pp. 584-591, (2012).

[3] Ahmed E. Mahfouz, and Ahmed S. Fahmy., "Fast Localization of the Optic Disc Using Projection of Image Features," IEEE TRANSACTIONS ON IMAGE PROCESSING, (2010).

[4] F. A. Hashim, N. M. Salem, and A. F. Seddik., "Optic Disc Boundary Detection from Digital Fundus Images," Journal of Medical Imaging and Health Informatics, 50-56 (2015).

[5] Javad Rahebi ,Firat Hardalaç., "A new approach to optic disc detection in human retinal images using the firefly algorithm," Medical biological engineering \& computing, 453-461 (2016).

[6] DongboZhang and YuanyuanZhao., "Novel Accurate and Fast Optic Disc Detection in Retinal Images With Vessel Distribution and Directional Characteristics," IEEE Journal of Biomedical and Health Informatics, 333-342 (2016). 
[7] Ivo Soares, Miguel Castelo-Branco, and Antonio M. G. Pinheiro., "Optic Disc Localization in Retinal Imagesbased on Cumulative Sum Fields," IEEE Journal of Biomedical and Health Informatics, 574-585 (2016).

[8] Li Xiongand, Huiqi Li., "An approach to locate optic disc in retinal images with pathological changes," Computerized Medical Imaging and Graphics, 40-50 (2016).

[9]S. Giraddi, Jagadeesh Pujariand, P. S. Hiremath., "Optic Disc Detection Using Geometric Properties and GVF snake,” Intelligent Systems and Information Management, (2017).

[10] M. Foracchia, E. Grisan, A. Ruggeri, "Detection of optic disc in retinal images by means of a geometrical model of vessel structure," IEEE Trans. Med. Imaging., 1189-1195 (2004).

[11] A. Youssif, A.Z. Ghalwash, and A.R. Ghoneim., "Optic disc detection from normalized digital fundus images by means of a vessels direction matched filter," IEEE Trans.Med.Imaging., 11-18 (2008).

[12] Xavier Zanlonghi., "Un comparatif de rétinographes non mydriatiques, " Slate, 2005, http:// http://www.ophtalmo.net/bv/Doc/2005-5918-XZ-RNM.pdfasp (20 Mars 2018).

[13] S.S. Kar, S.P. Maity., "Detection of neovascularization in retinal images using mutual information maximization," Computers and Electrical Engineering, 1-15 (2017).

[14] A. García-Floriano et al.,"A machine learning approach to medical image classification: Detecting age-related macular degeneration in fundus images, " Computers\& Electrical Engineering, 1-12(2017).

[15] Muthu Rama Krishnan Mookiah et al., "Automated detection of age-related macular degenerationusing empirical mode decomposition,” Knowledge-Based Systems, 654-668(2015).

[16] Carla Agurto, Honggang Yu, Victor Murray, MariosS.Pattichis, Sheila Nemeth, Simon Barriga, Peter Soliz., "A MultiscaleDecomposition Approach to Detect Abnormal Vasculature in the Optic Disc," Computerized Medical Imaging and Graphics, 137-149(2015). 